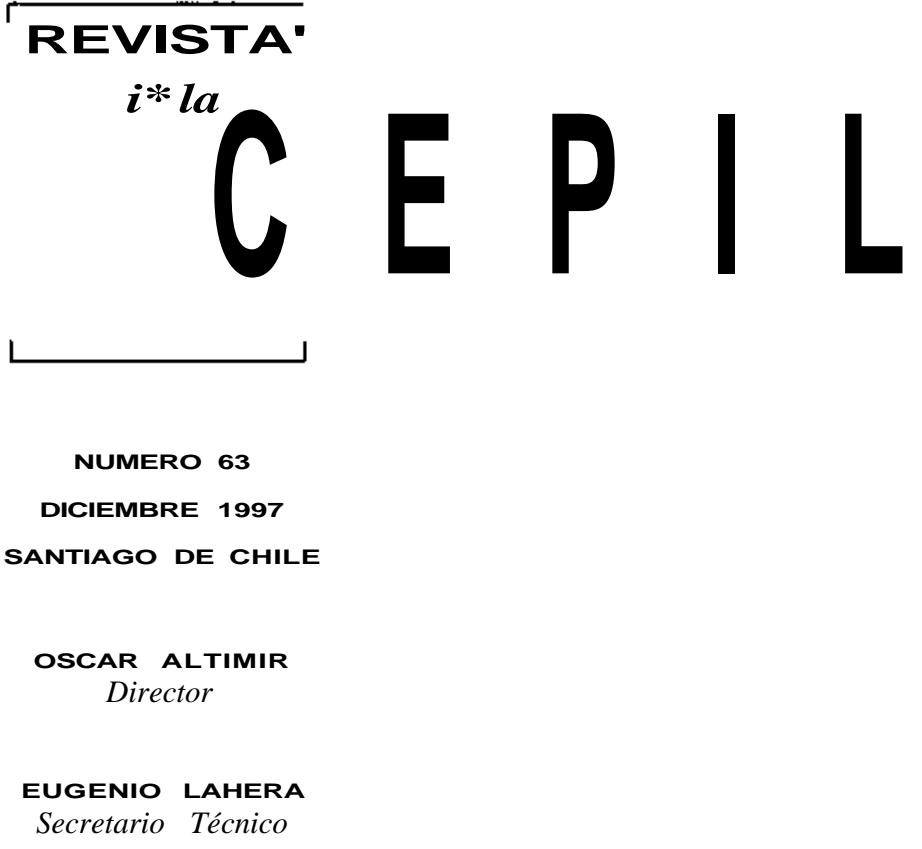

Secretario Técnico

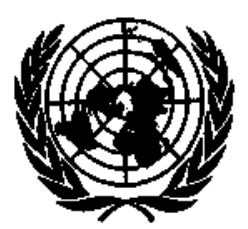

NACIONES UNIDAS 
El papel del sector público en el desarrollo latinoamericano

Ricardo Carciofi

La equidad en el presupuesto público

Juan Martin

Reformas a los sistemas de pensiones, mercado de capitales y ahorro

Andras Uthoff

Institucionalidad pública y políticas ambientales explícitas

e implícitas

Nicolo Gligo

La valoración de recursos naturales y ambientales no basada en el mercado en Centroamérica y el Caribe

Steve Shultz

Un modelo macroeconómico integrado para el Caribe

Lucio Vinhas de Souza

Virajes y derrapajes de la economía venezolana

José Miguel Benavente

¿Cuan no tradicionales son las exportaciones no tradicionales?

La experiencia de siete países de la Cuenca del Caribe

Alberto Gabriele

Apertura comercial y cambio estructural en la industria automotriz brasileña

Ruy de Quadros Carvalho, Sergio Robles Reis de Queiroz,

Flávia Luciane Consoni, loriara Costa y Janaína Pamplona da Costa

Historia evolutiva de una planta metalmecánica chilena

Jorge Katz y Héctor Vera

La importancia de lá producción local y la pequeña empresa para el desarrollo de América Latina

Francisco Alburquerque

Publicaciones recientes de la CEPAL 


\section{La importancia de la producción local y la pequeña empresa para el desarrollo de América Latina}

\section{Francisco Alburquerque}

Investigador del Consejo

Superior de Investigaciones Científicas (csic) de España, Ex Director de Desarrollo y Gestión Local del Instituto Latinoamericano y del Caribe de Planificación Económica y Social (ILPES)
La generación de ventajas competitivas dinámicas en América Latina y el Caribe no puede confiarse exclusivamente al logro de la necesaria estabilidad macroeconómica y a la inserción de parte del tejido productivo en algunos segmentos (o nichos) dinámicos en el ámbito internacional. La información empírica reciente sobre el despliegue de iniciativas de desarrollo económico local en los países desarrollados indica que es preciso acompañar las políticas de ajuste macroeconómico con otras políticas específicas a nivel microeconómico y mesoeconómico. Estas políticas deben incorporar a los diferentes actores territoriales, públicos y privados, en la estrategia de desarrollo a fin de asegurar la introducción de innovaciones tecnológicas y organizativas en la totalidad del tejido productivo y empresarial, que está compuesto mayoritariamente de empresas pequeñas y medianas y microempresas con poca inserción en el núcleo globalizado de la economía mundial. De las consideraciones anteriores se desprende tanto la necesidad de promover el potencial de desarrollo endógeno, asignando la importancia debida a la dimensión territorial de la política tecnológica y a la atención a las pequeñas y medianas empresas, como la de asegurar el acceso a servicios avanzados a la producción en el entorno territorial, el afianzamiento de las redes institucionales y acuerdos de cooperación y complementariedad territoriales, y la inclusión de la sustentabilidad ambiental en la gestión local del desarrollo. 


\section{Introducción}

En América Latina y el Caribe la difusión de conceptualizaciones, análisis y recomendaciones de política relativos a la globalización y la competitividad suele acompañarse de interpretaciones que apenas trascienden la esfera de la circulación de los mercados internacionales. Sin embargo, debiera estar claro que en la fase actual de transición posfordista la construcción de las ventajas competitivas dinámicas descansa también, de forma sustantiva, en esfuerzos organizados y actuaciones específicas orientadas a asegurar la introducción de innovaciones tecnológicas y organizativas en el tejido productivo y empresarial existente, que está conformado mayoritariamente por empresas pequeñas y medianas y microempresas, que por no tener acceso fácil a los servicios avanzados a la producción ven considerablemente dificultado su avance hacia la frontera tecnológica deseable.

En otras palabras, los retos de la competitividad exigen no sólo ocuparse de los segmentos de producción que se eslabonan con el núcleo dinámico globalizado de la economía mundial, sino acompañar dichos esfuerzos exportadores con medidas orientadas a asegurar la innovación tecnológica y organizacional de las diferentes aglomeraciones productivas (clusters) locales. La importancia de estas aglomeraciones suele ser omitida, aunque como lo confirma el despliegue de iniciativas de desarrollo económico local en los países desarrollados, se requieren políticas específicas de construcción o acondicionamiento de entornos territoriales innovadores, para contar con los componentes apropiados de innovación y de gestión de los recursos humanos en cada territorio .

Desde luego, no se propone aquí imitar - lo que es siempre imposible - experiencias relativamente exitosas en otros contextos, como la de los distritos industriales italianos o las agencias de desarrollo regional en el actual Estado español de las Comunidades Autónomas. En este, como en tantos otros campos, no hay recetas, pero sí ideas fértiles para abandonar una concepción de los procesos de ajuste limitada sólo a los niveles macroeconómicos y la competitividad internacional. En la heterogénea situación latinoamericana y caribeña actual, acompañar estas políticas con otras de contenido territorial dirigidas a la concertación de actores públicos y privados para la construcción de entornos innovadores de su actividad productiva y empresarial no sólo resulta posible, sino altamente recomendable.

\section{II}

\section{La importancia de la producción de ámbito local}

Según datos recientes del Banco Mundial (1996), del total de la producción bruta mundial que se contabiliza en los circuitos formales de la economía, en promedio apenas un $20 \%$ se comercializa internacionalmente. Es decir, la gran mayoría de las decisiones de producción tienen lugar en escenarios nacionales o subnacionales, regionales o locales. En algunos países, el porcentaje de la producción nacional que se comercializa internacionalmente es mayor. Pero en otros, como Japón, es sólo de $9 \%$ (cuadro 1): la fortaleza de esta economía, además de responder a su agresividad comercial externa, parece descansar esencialmente en el grado de articulación sectorial y eficiencia productiva internas.
Igualmente (cuadro 2), la participación media de las exportaciones en el producto interno bruto (PIB) de 19 países de América Latina y el Caribe en 1994 era de $23 \%$, lo que quiere decir que en promedio más del $77 \%$ de la producción de los países latinoamericanos y caribeños correspondía, en ese año, al ámbito nacional o local.

Por otra parte, la participación de la inversión extranjera directa en el producto interno bruto de los países de América Latina y el Caribe, según estimaciones de la CEPAL (1996), fue sólo 1.6\% en 1996 (cuadro 3 ), lo que también nos indica la importancia de las decisiones internas de inversión productiva en dichos países, donde la inversión media es cercana al $20 \%$ del PIB. 
Mundo: Producción y exportaciones, 1994

\begin{tabular}{|c|c|c|}
\hline & $\begin{array}{c}\mathrm{PIB} \\
\text { (Miles de millones } \\
\text { de dólares corrientes) }\end{array}$ & $\begin{array}{c}\text { Participación de las } \\
\text { exportaciones en el PIB } \\
\text { (Porcentajes) }\end{array}$ \\
\hline Mundo & $25 \quad 102.6$ & 19.7 \\
\hline Japón & 4321.1 & 9 \\
\hline Estados Unidos & 6737.4 & 10 \\
\hline India & 278.7 & 12 \\
\hline Australia & 320.7 & 19 \\
\hline España & 525.3 & 19 \\
\hline Turquía & 149.0 & 21 \\
\hline Alemania & 2075.5 & 22 \\
\hline Grecia & 80.2 & 22 \\
\hline Francia & 1355.0 & 23 \\
\hline Reino Unido & 1069.5 & 25 \\
\hline Indonesia & 167.6 & 25 \\
\hline China & 630.2 & 26 \\
\hline Portugal & 92.1 & 26 \\
\hline Federación Rusa & 392.5 & 27 \\
\hline \multicolumn{3}{|l|}{ República de } \\
\hline Corea & 366.5 & 28 \\
\hline Suecia & 206.4 & 33 \\
\hline Dinamarca & 145.4 & 34 \\
\hline Suiza & 265.0 & 36 \\
\hline Austria & 197.5 & 38 \\
\hline Holanda & 338.1 & 51 \\
\hline Bélgica & 231.0 & 69 \\
\hline Hong Kong & 126.3 & 139 \\
\hline
\end{tabular}

Fuente: Banco Mundial (1996); Ffrench-Davis (1996a y 1996b).

CUADRO 2

América Latina: Producción, exportaciones e inversión, 1994

\begin{tabular}{lccc}
\hline & $\begin{array}{c}\text { PIB } \\
\text { (miles de millones } \\
\text { de dólares } \\
\text { corrientes) }\end{array}$ & \multicolumn{2}{c}{$\begin{array}{c}\text { Participación en el PIB } \\
\text { (porcentajes) }\end{array}$} \\
\hline Brasil & 536.3 & 7 & 16 \\
Exportaciones & Inversión \\
Argentina & 275.6 & 7 & 20 \\
Perú & 44.1 & 9 & 22 \\
México & 369.7 & 13 & 24 \\
El Salvador & 8.4 & 13 & 18 \\
Bolivia & 5.6 & 17 & 15 \\
Colombia & 58.9 & 17 & 24 \\
Uruguay & 14.7 & 18 & 16 \\
Guatemala & 12.2 & 19 & 17 \\
República Dominicana & 10.1 & 24 & 20 \\
Nicaragua & 1.4 & 24 & 20 \\
Ecuador & 14.7 & 26 & 21 \\
Paraguay & 7.6 & 27 & 24 \\
Chile & 50.0 & 28 & 27 \\
Venezuela & 59.0 & 29 & 9 \\
Panamá & 6.9 & 37 & 24 \\
Costa Rica & 7.8 & 40 & 28 \\
Trinidad y Tabago & 4.8 & 40 & 14 \\
Honduras & 3.2 & 41 & 26 \\
\hline
\end{tabular}

Fuente: Banco Mundial (1996); Ffrench-Davis, R. (1996a y 1996b).
CUADRO 3

América Latina: Inversión extranjera directa y producto interno bruto

\begin{tabular}{lcc}
\hline & $\begin{array}{c}\text { Inversión extranjera } \\
\text { directa (IED) neta } \\
\text { (millones de dólares) }\end{array}$ & $\begin{array}{c}\text { Relación entre la } \\
\text { IED y el PIB }\end{array}$ \\
\cline { 2 - 3 } & $1996^{\mathrm{a}}$ & $1995-1996^{\mathrm{b}}$ \\
\hline Argentina & 3200 & 1.2 \\
Bolivia & 560 & 6.5 \\
Brasil & 8000 & 0.8 \\
Chile & 2800 & 2.8 \\
Colombia & 2550 & 2.8 \\
Costa Rica & 120 & 2.5 \\
Ecuador & 320 & 2.2 \\
México & 7000 & 2.7 \\
Nicaragua & 95 & 3.9 \\
Paraguay & 220 & 2.2 \\
Perú & 3400 & 4.4 \\
República Dominicana & 430 & 2.6 \\
Uruguay & 190 & 0.9 \\
Venezuela & 1350 & 1.3 \\
Otros siete países & 600 & \\
América Latina y & & \\
el Caribe & 30835 & 1.6 \\
\hline
\end{tabular}

Fuente: CEPAL, sobre la base de cifras oficiales y del FMI.

a Estimaciones provisionales.

$\wedge$ Promedio anual. Estimaciones preliminares.

Asimismo, tal como señala Ffrench-Davis (1996a y 1996b), la inversión externa es solamente el 5\% de la inversión total mundial, mientras que los flujos de inversión extranjera directa equivalen únicamente al $1 \%$ del PIB mundial. Esto quiere decir que la inmensa mayoría de las decisiones de inversión productiva y empresarial corresponde a actores que se desenvuelven en ámbitos nacionales o subnacionales. No estamos, pues, como nos recuerda ese autor, ante el "final de la geografía" ni mucho menos.

Es posible que, asombrados por los altos ritmos de crecimiento del comercio internacional y el avance de la globalización, se tienda a olvidar la magnitud de la producción, comercio e inversión internas, y el hecho crucial de que la gran mayoría de las decisiones en esas actividades corresponde a ámbitos nacionales y locales, lo cual quiere decir que existe un amplio margen para el diseño de políticas económicas territoriales, tanto a nivel microeconómico como mesoeconómico.

Así pues, si bien es cierto que la identificación de las mejores prácticas en el contexto internacional y la búsqueda de segmentos de mercado a ese nivel constituyen acciones necesarias para introducir tensión innovativa en los procesos productivos y la gestión empresarial, no hay que olvidar que esto último no se logra fácilmente, pues se requiere para ello de políti- 
cas específicas en los niveles microeconómico y mesoeconómico.

Por otra parte, las estadísticas citadas anteriormente no incluyen otros circuitos de actividad importantes, tales como la economía de autoconsumo o la economía informal, lo cual resalta aún más la atención que merecen los procesos locales, además de la que se otorga a los fragmentos internacionalizados o globalizados.

Lo que estas estadísticas muestran, en definitiva, es que incluso con las limitaciones que las mismas contienen al no incluir las transacciones informales y de más difícil cuantificación, la generación y distribución de riqueza en los espacios nacional y subnacional dependen en gran medida de las políticas e institucionalidad territoriales específicas que los diferentes actores sociales, a partir de iniciativas locales, logren concertar con miras al fomento económico endógeno a fin de alcanzar niveles de eficiencia productiva adecuados y contribuir así a la difusión del crecimiento económico y la generación de empleo e ingreso.

A pesar de esta evidencia empírica, el diseño de las políticas de desarrollo parece responder más al debate entre ideologías, con el lamentable resultado de que con frecuencia se acaba invitando a los gobernantes y a gran parte de los actores sociales de los países en desarrollo a buscar nichos en el mercado internacional como si de ello dependiera su desarrollo económico cuando lo que se requiere fundamentalmente es contar con adecuadas estrategias nacionales y territoriales de desarrollo, que aseguren la introducción y difusión de las innovaciones tecnológicas y organizativas en los diferentes sistemas económicos nacionales y locales.

Dicho en otras palabras, las estrategias para la inserción en segmentos dinámicos de la economía internacional deben ser complementadas con una decidida política de fomento de los sistemas productivos locales, a fin de asegurar en ellos la innovación tecnológica y organizacional necesaria. Este tipo de políticas permite, además, sustentar la viabilidad a mediano y largo plazo de las apuestas realizadas en los segmentos internacionales.

Según datos del Banco Mundial (1996), en los países con exportaciones inferiores al $10 \%$ de la producción nacional el PIB por habitante dobla con creces el del grupo de economías donde dicha cifra se halla entre el 10 y el $24 \%$, y más que triplica el del grupo de países donde es superior a 25\% (cuadro 4). Estos datos aconsejan matizar la afirmación de que el mayor desarrollo económico depende del grado de internacionalización de la producción interna de las diferentes economías.

Aunque con una buena selección y manejo de las estadísticas se puede casi siempre acabar demostrando cualquier argumento, es obvio que el logro de mayor capacidad exportadora es un reflejo de la eficiencia productiva y la competitividad empresarial, y que el comercio internacional procura posibilidades de progreso y nuevos conocimientos. Sin embargo, y esto resulta decisivo, para concretar tales posibilidades es determinante el grado en que se consigue asegurar la difusión de las innovaciones tecnológicas y organizativas en el sistema productivo y empresarial interno, que no consta únicamente de las empresas que logran insertarse exitosamente en los núcleos dinámicos internacionales.

Por supuesto, no se pretende aquí entonar alabanzas a la autarquía, sino formular una sensata recomendación a favor del necesario reforzamiento de las economías nacionales y locales, tratando de no dejarse arrastrar por las frecuentes invitaciones a la simple búsqueda de nichos internacionales, como si ello fuera el talismán definitivo para lograr el deseado desarrollo económico. Aceptar los retos de las crecientes apertura externa y competitividad internacional supone, en definitiva, la exigencia de introducir innovaciones tecnológicas y organizativas en todo el sistema productivo interno de nuestras economías, así como en las instituciones apropiadas, y no sólo en las activida-

CUADRO 4

Mundo: Población y producto interno bruto de países clasificados según la participación de sus exportaciones en su PIB, 1994

\begin{tabular}{|c|c|c|c|c|}
\hline Exportaciones/PIB & $\begin{array}{l}\text { Número de } \\
\text { países }\end{array}$ & $\begin{array}{c}\text { PIB } \\
\text { (Miles de millones } \\
\text { de dólares) }\end{array}$ & $\begin{array}{l}\text { Población } \\
\text { (Millones de } \\
\text { habitantes) }\end{array}$ & $\begin{array}{l}\text { PIB_por habitante } \\
\text { (dólares) }\end{array}$ \\
\hline Menos de $10 \%$ & 10 & 5250 & 448 & 11610 \\
\hline Entre 10 y $24 \%$ & 51 & 6859 & 2551 & 5765 \\
\hline Más de $24 \%$ & 102 & 5270 & 2429 & 3620 \\
\hline Sin datos & 46 & 508 & 176 & 2890 \\
\hline
\end{tabular}

Fuente: Elaborado a partir de datos del Banco Mundial (1996). 
des y empresas vinculadas a los segmentos dinámicos internacionales.

Así pues, en la actual fase de globalización de la economía mundial, con crecientes demandas de eficiencia productiva y competitividad, y en escenarios en los que la mayor apertura externa de las diferentes economías nacionales y territoriales constituye un dato del contexto imperante, conviene no olvidar que los retos principales radican en asegurar la introducción de innovaciones de gestión y productivas en el sistema empresarial y en el conjunto de las organizaciones de gestión, públicas o privadas, a fin de elevar la eficiencia productiva y la flexibilidad (o capacidad de adaptación) en escenarios variables e inciertos (Alburquerque, 1996a).

En otras palabras, la fase de transición tecnológica por la que atravesamos hace imperativo encontrar la manera de asegurar que se produzca la innovación productiva y de organización en el conjunto de las empresas existentes en cada país, lo que no puede lograrse con la sola inserción de algunos segmentos o actividades económicas en los núcleos dinámicos de la economía mundial. Tales nexos externos no siempre garantizan que el progreso técnico se difunda a todas las empresas del conjunto de territorios del país: los eslabonamientos entre los sectores vinculados a los núcleos dinámicos y los sistemas productivos locales pueden ser muy limitados, con lo cual la difusión del progreso técnico, el crecimiento económico, el empleo y el ingreso sería escasa.

Igualmente, en los sistemas productivos locales abundan las empresas pequeñas, las que si bien son menos importantes que las grandes empresas en términos de valor agregado a la producción nacional, tienen un peso decisivo en el empleo y la generación de ingresos, así como en la difusión territorial más equilibrada del crecimiento económico. Pese a ello, tales empresas no suelen disponer en América Latina y el Caribe de una oferta territorial adecuada de infraestructura básica y servicios empresariales avanzados para facilitar su proceso de modernización. Se precisan, por lo tanto, reformas institucionales apropiadas a fin de incorporar en el proceso de descentralización que se lleva a cabo en gran parte de la región elementos de fomento económico y de impulso a la concertación estratégica de los actores sociales territoriales para la construcción de entornos innovadores.
Esto no supone incurrir en la fantasía de recrear los "distritos industriales" según la rica experiencia reciente de la Tercera Italia o de algunas Comunidades Autónomas del Estado español, por citar sólo dos ejemplos importantes en este terreno. Unicamente resalta la necesidad de añadir adecuadas políticas territoriales de desarrollo a las políticas sectoriales y las dirigidas a las grandes empresas, con el fin de asegurar la innovación tecnológica de los sistemas productivos locales en su conjunto y no sólo de los segmentos capaces de insertarse en actividades dinámicas externas.

Dicho todo esto, hay que resaltar también que la rápida movilidad transfronteriza de las inversiones financieras y de la información sobre mercados, productos y tecnologías, la extensión de gustos y preferencias de consumo uniformes a través de los medios de comunicación, así como la facilidad para trasladar segmentos o partes de las actividades productivas, socavan de manera importante la eficacia de las políticas económicas nacionales a la hora de encarar las estrategias de las empresas transnacionales. Igualmente, la definición de políticas de fomento económico desde la administración central del Estado no resulta apropiada ni eficiente para lograr la modernización de los sistemas locales de empresas, que requieren una institucionalidad mucho más cercana a sus problemas, potencialidades y especificidad.

Las fuerzas económicas que impulsan hoy el cambio hacia formas de producción y organización más eficientes (tanto en la esfera empresarial privada como en las administraciones públicas) están cuestionando, por consiguiente, la eficacia del Estado central como entidad suficiente para actuar sobre la compleja realidad económica y para intentar gestionarla. Y puesto que el Estado-nación ya no es el único vertebrador de los sistemas económicos (los que tienen un mayor grado de exposición, y por ende de vulnerabilidad, en el escenario de la globalización y están sometidos a la tensión de diferentes lógicas de funcionamiento, unas con miras a la transnacionalización y otras a los mercados locales), en este proceso de readaptación económica e institucional es preciso considerar las circunstancias nacionales y territoriales, a fin de conocer sus diferencias y potencialidades y definir la combinación de políticas más apropiada en los diferentes niveles de desarrollo económico, acción que ya no es monopolio de la administración central del Estado. 
III

\section{Los diferentes niveles y políticas del desarrollo económico}

Dada la creciente exposición externa de todos los sistemas económicos es fundamental, aunque no suficiente, asegurar la máxima estabilidad en el plano macroeconómico. Debe actuarse además en el plano microeconómico de la transformación productiva y organizacional, lo que exige abordar a la vez las adaptaciones institucionales que conlleva todo proceso de cambio tecnoproductivo radical, al alterar las relaciones sociales, laborales, productivas y otras entre los diferentes actores de la sociedad.

Así pues, las exigencias de la globalización no tienen que ver únicamente con las actividades vinculadas a los mercados internacionales, sino que afectan de forma decisiva el nivel macroeconómico, que debe asegurar las condiciones de estabilidad requeridas por el régimen de acumulación; el nivel microeconómico, en el que deben abordarse los cambios tecnológicos en la producción y la gestión empresarial, y el nivel mesoeconómico, en el que deben crearse la institucionalidad y las organizaciones intermedias que han de concretar en cada territorio los entornos innovadores para el desarrollo económico local.

A los niveles señalados cabe añadir el nivel meta. Así lo afirman Esser, Hillebrand, Messner y MeyerStamer (1996), para quienes la competitividad estructural o sistémica es resultado del nivel organizativo e institucional alcanzado por la interacción de toda la sociedad, y depende no sólo del nivel macro (asegurador de la estabilidad necesaria para permitir la reproducción del régimen de acumulación), sino de la capacidad de animación social y de concertación estratégica de los actores territoriales (nivel meta), de la creación a nivel meso del entorno innovador apropiado para el fomento empresarial, y de que se garantice efectivamente la innovación tecnológica y organizacional en el nivel micro de la actividad productiva y empresarial de cada territorio.

Desde esta perspectiva se aprecia, pues, que la gestión pública descentralizada desempeña un papel decisivo, toda vez que la formulación de políticas apropiadas para la transformación productiva y empresarial requiere un conocimiento minucioso (y no sólo a nivel agregado nacional) de las circunstancias y perfi- les concretos de las diferentes aglomeraciones económicas territoriales significativas (Alburquerque, 1996b).

De esta manera, las políticas económicas sectoriales podrían verse acompañadas de este componente territorial a fin de asegurar la transformación productiva y empresarial en el nivel micro, para lo cual un planteamiento descentralizado o territorializado facilita la mejor comprensión de las circunstancias concretas de la base productiva y el tejido empresarial en cada territorio.

Esto es mucho más evidente en la fase actual del desarrollo económico, en la cual la deslocalización y segmentación de las diferentes fases de la actividad productiva, así como la subcontratación de empresas, han mostrado la superior eficiencia de las formas de organización y producción flexibles, con capacidad de funcionar en redes (Messner, 1996).

Habrá que insistir, en todo caso, en que la empresa no actúa en el vacío sino en un determinado entorno territorial, que tiene una calidad e interrelaciones determinadas y que influye decisivamente en el nivel de eficiencia productiva y competitividad de la empresa. La dotación, calidad y orientación de la infraestructura básica, las características del sistema educativo y de capacitación territorial, el mercado de trabajo local, el sistema de salud territorial, los servicios avanzados a la producción, la investigación científica y tecnológica, y la cultura local en materia de desarrollo, entre otros, son componentes que permiten impulsar desde el territorio la eficiencia productiva y la competitividad de las empresas en él radicadas (gráfico 1). De este modo, la simplificación y frecuente exaltación de los denominados "riesgos empresariales" parecen olvidar que tras de los empresarios existe todo este esfuerzo organizado $-\mathrm{y}$ financiado- por el conjunto de la sociedad, del cual depende esencialmente el logro de la competitividad.

Así, los territorios (regiones, microrregiones o confederaciones de municipios) cuyos actores públicos y privados sepan construir entornos innovadores a partir de sus propios recursos y circunstancias ante los retos que plantean tanto las nuevas formas de produc- 


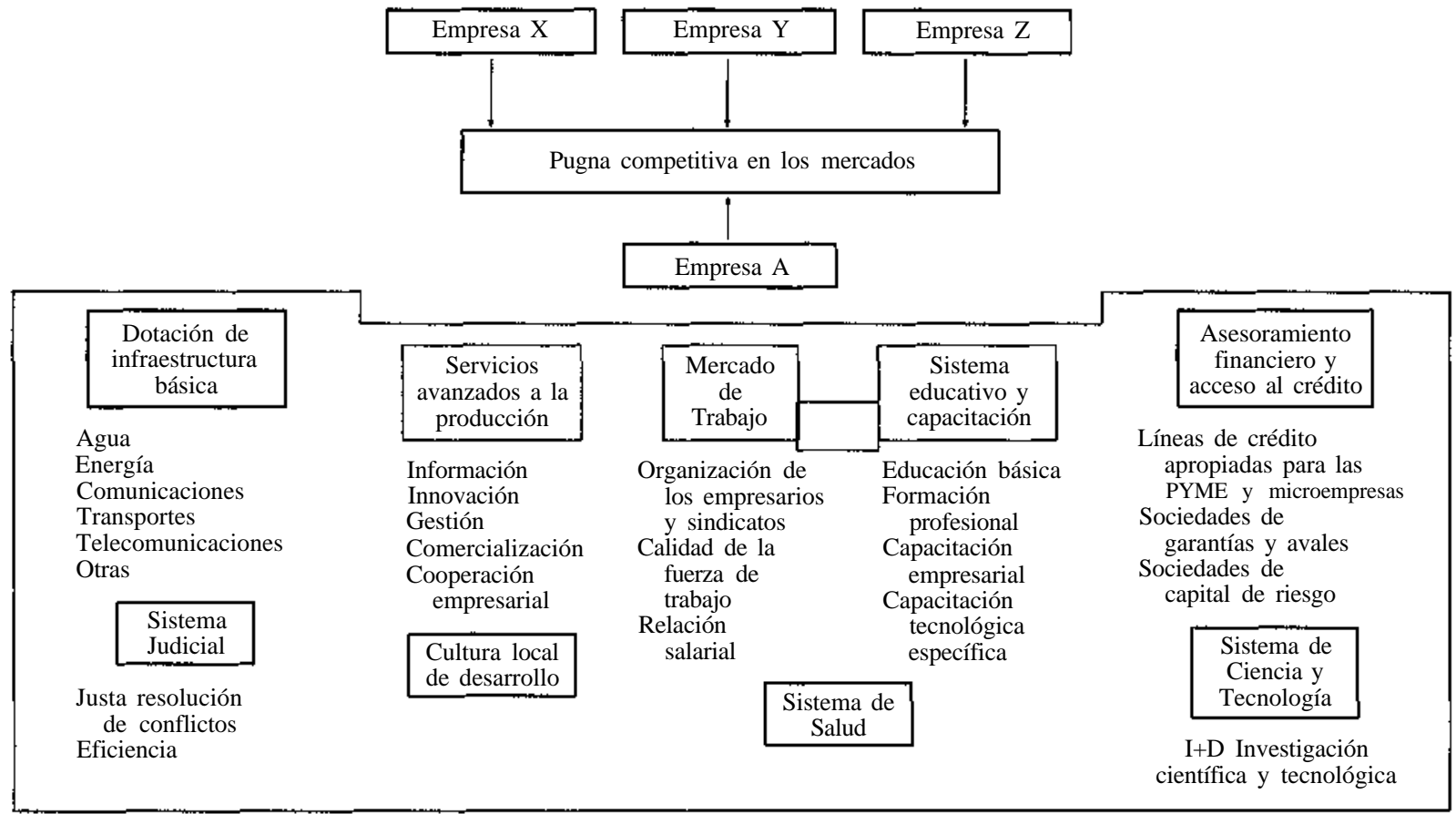

ción y gestión como la creciente internacionalización de las economías y las pautas de consumo, están lla- mados a ser agentes eficaces de su propia transformación tecnológica y socioeconómica.

\section{IV}

\section{El redescubrimiento de la dimensión territorial}

La globalización ha ayudado pues a redescubrir la dimensión territorial, ya que ha sido detonante de una redistribución general de la actividad en el territorio; al mismo tiempo, las actividades productivas territoriales y sistemas locales de empresas perciben ahora con mayor nitidez las grandes exigencias de eficiencia productiva y competitividad a las que están expuestas.

Ahora bien, la variedad de entornos territoriales es contradictoria sólo en apariencia con el avance de la globalización, ya que ésta puede sacar provecho de dicha diferenciación territorial, siempre que a las políticas de ajuste macroeconómico se sumen políticas microeconómicas y mesoeconómicas que estimulen comportamientos, entornos e instituciones territoriales, a fin de mejorar la eficiencia y la competitividad de los sistemas productivos y empresariales locales.
Como se sabe, en la fase actual de la revolución posfordista el conocimiento es la fuerza decisiva en la reorganización de la producción y el espacio, así como en la introducción de los mejores métodos de gestión y organización de las empresas públicas o privadas.

Igualmente, los avances en la difusión y comunicación de conocimientos estimulan la globalización. Y del mismo modo, la diversidad territorial descansa en la adquisición y adaptación de conocimientos generales y específicos, filtrados por la práctica, institucionalidad y cultura locales.

Así, el territorio es uno de los contextos en que se desarrolla la división del trabajo cognoscitivo, es decir, la división del trabajo en la actividad de producción y utilización de los conocimientos; éstos pueden llamarse "contextúales" cuando se producen en el 
medio local y son de alguna forma específicos de dicho territorio, y "codificados" cuando son de carácter global, más fácilmente transferibles (Becattini y Rullani, 1996, p. 12).

Siguiendo la argumentación de estos autores, los conocimientos codificados sólo pueden utilizarse adecuadamente si se les recontextualiza en los ambientes productivos particulares o locales; del mismo modo, es preciso codificar algunos de los conocimientos contextúales, si se quiere hacerlos transferibles y conseguir de ese modo economías de escala suficientes.

Vemos así que las relaciones entre los niveles local y global no son necesariamente antagónicas. En palabras de Becattini y Rullani (1996, p. 12), lo que hay es una división del trabajo cognoscitivo de tipo circular, pues lo local genera conocimientos para uso global y lo global suministra a los circuitos locales conocimientos procedentes de todo el mundo.

Esto no oculta, desde luego, que el avance de la globalización impone mayores exigencias a todos los sistemas económicos territoriales, y que algunos de ellos tal vez no sobrevivan en los escenarios de superior pugna competitiva que supone la globalización, sobre todo si sólo reaccionan de manera defensiva o denunciatoria de la "modernidad", en lugar de buscar activamente las oportunidades de alcanzar superior especialización, calidad y diversificación productiva internas.

Para hacer esto último se necesitan estrategias y políticas específicas de desarrollo territorial, y no solamente orientaciones genéricas y centralistas que normalmente se limitan a combinar insuficientes (aunque necesarias) políticas macroeconómicas con otras dirigidas a favorecer la inserción en algunos nichos internacionales dinámicos, como si ello bastase para asegurar la innovación tecnológica y organizativa en todos los sistemas productivos y empresariales.

En los años de posguerra, en que el fordismo constituyó la forma hegemónica de organizar la producción en los países centrales, se fue dejando de lado gradualmente la dimensión territorial del desarrollo. El predominio de la gran empresa y la producción en serie, así como la paulatina disminución del costo de los transportes y comunicaciones, contribuyeron poderosamente a ello. La lógica de la distribución espacial de la producción se derivaba entonces, esencialmente, de la lógica empresarial y no de una territorial. En pocas palabras, eran la lógica sectorial y la planificación empresarial, con los componentes jerárquicos propios del modelo organizativo fordista, las que establecían las pautas principales de desenvolvimiento económico, siendo los recursos territoriales "extraídos" de su contexto para ser incorporados a la lógica empresarial (Becattini y Rullani, 1996, p. 13).

No obstante, a partir de los años setenta, la evidencia de los distritos industriales italianos y el mayor desarrollo alcanzado por Japón y los países asiáticos de industrialización reciente iba a mostrar la reducida capacidad interpretativa de las formulaciones teóricas anteriores. La crisis del fordismo es, pues, también la crisis de las teorías sobre el desarrollo predominantes, las que habían sustituido la alusión al territorio por la lógica abstracta de las categorías macroeconómicas y las economías de escala de la producción.

Sin embargo, como muestran los ejemplos de Japón, de los países asiáticos de industrialización reciente y de los distritos industriales italianos, los factores territoriales y la diferenciación institucional y cultural, así como la existencia de estrategias nacionales de desarrollo concertadas por los diferentes actores sociales, públicos y privados, contribuyen de manera sustantiva al desarrollo económico, pues permiten lograr rendimientos crecientes en la adquisición de conocimientos gracias a las economías de aglomeración territorial.

La transición al postfordismo se ve acompañada de un fenómeno crucial, cual es la posibilidad de efectuar una transferencia transcontextual de los conocimientos por parte de las empresas y territorios, lo que obliga a unas y otros a dominar los lenguajes formales de la comunicación a distancia, a fin de poder trabajar en redes. Esto plantea graves problemas, sobre todo a las PYME, las microempresas y los sistemas productivos locales, si carecen de un entorno apto y experimentado. De ahí que sea tan necesario acondicionar los diferentes territorios en este sentido.

Como vemos, el territorio es considerado un recurso específico y un actor principal del desarrollo económico y no un espacio o marco de las actividades económicas o sociales. En opinión de Becattini y $\mathrm{Ru}$ llani (1996, p. 15), el territorio produce efectos en la economía local y le ofrece prestaciones específicas. Suministra a la producción para el consumo una prestación de "integración flexible" o, en otras palabras, un entorno capaz de generar y mantener ventajas competitivas y un valor diferencial.

La creación de este "entorno innovador" territorial no es fácil de reproducir, y son precisamente la densidad y la calidad de las relaciones entre los diferentes actores territoriales las que potencian a dicho territorio como circuito específico de interacciones orientadas al fomento empresarial, la innovación productiva, la calidad de los recursos humanos y de las relaciones laborales y el impulso de la cultura local de desarrollo, todos ellos elementos cruciales de la competitividad. 
De nuevo habrá que insistir en que si bien el caso de la región latinoamericana y caribeña difiere del observado en otros escenarios, como el de los distritos industriales italianos, siempre es factible trabajar desde la perspectiva del desarrollo regional endógeno, acompañando de este modo las políticas de ajuste macroeconómico impulsadas por las instancias centrales de la administración del Estado.

\section{Importancia de la PYME y la microempresa}

En América Latina y el Caribe, al igual que en el mundo desarrollado, la pequeña producción ocupa un lugar muy destacado, sobre todo en la generación de empleo e ingreso para amplias capas de la población, y en la difusión territorial del progreso técnico y el crecimiento económico. Por eso, la falta de políticas específicas frente a los problemas concretos de este tipo de empresas en los diferentes sistemas productivos locales limita considerablemente cualquier estrategia de desarrollo económico. Sin embargo, no sería suficiente la existencia de un programa genérico de apoyo a las PYME y las microempresas desde el Estado central. Creo que habría que identificar los diferentes sistemas locales de empresas y construir en cada caso, y de forma concertada con los diferentes actores sociales públicos y privados del territorio, los entornos innovadores más apropiados.

Un vistazo a la información sobre la importancia de la pequeña empresa de tipo formal ${ }^{1}$ en varios países de América Latina (cuadro 5), nos muestra que el

1 Nótese que la inclusión de las empresas del sector informal haría aún más pertinentes las afirmaciones que aquí se exponen.

CUADRO 5

América Latina: Importancia de la pequeña empresa"

\begin{tabular}{|c|c|c|c|}
\hline & $\begin{array}{l}\text { Tamaño de las empresas } \\
\text { según el número de } \\
\text { empleados }\end{array}$ & $\begin{array}{l}\text { Número de } \\
\text { establecimientos } \\
(\% \text { del total }) \\
\end{array}$ & $\begin{array}{l}\text { Distribución } \\
\text { del empleo } \\
<\% \text { del total) }\end{array}$ \\
\hline Colombia" & $\begin{array}{l}\text { Micro (Hasta 9) } \\
\text { Pequeña (10-49) } \\
\text { Mediana (50-199) } \\
\text { Grande (Más de 200) }\end{array}$ & $\begin{array}{r}91.9 \\
4.3 \\
0.6 \\
0.2\end{array}$ & $\begin{array}{l}19.19^{\mathrm{C}} \\
30.37^{\mathrm{c}} \\
50.44^{\mathrm{c}}\end{array}$ \\
\hline Costa Rica ${ }^{\mathrm{d}}$ & $\begin{array}{l}\text { Micro (Entre } 1 \text { y } 4 \text { ) } \\
\text { PYME (5-99) } \\
\text { Grande (Más de 200) }\end{array}$ & $\begin{array}{l}84.4 \\
10.8^{\circ}\end{array}$ & $\begin{array}{r}47.8 \\
45.7 \\
6.1\end{array}$ \\
\hline Chile $^{\mathrm{f}}$ & $\begin{array}{l}\text { Micro (Hasta 9) } \\
\text { Pequeña }^{\wedge} \\
\text { Mediana }^{8} \\
\text { Grande (Más de 200) }\end{array}$ & $\begin{array}{c}82.88 \\
14.48 \\
1.3 \\
1.5\end{array}$ & $\begin{array}{l}43.3 \\
36.5^{\mathrm{h}} \\
20.2\end{array}$ \\
\hline México' & $\begin{array}{l}\text { Microempresas } \\
\text { y PYME } \\
\text { manufactureras }\end{array}$ & 98.0 & $\begin{array}{l}49 \% \text { del } \\
\text { empleo } \\
\text { industrial }\end{array}$ \\
\hline
\end{tabular}

a Los datos se refieren solamente al sector formal de la economía, esto es, infravaloran la importancia de la pequeña producción.

b Censo Económico Nacional, 1990.

* Datos de empleo en industrias manufactureras de más de 10 empleados.

‘ Censo Económico, Ministerio de Economía, Industria y Comercio, 1991; Caja Costarricense del Seguro Social, Centro de Información Industrial, 1994.

$\mathfrak{k}$ Este porcentaje corresponde solamente al número de establecimientos entre 5 y 19 empleados.

I Fundación Friedrich Ebert/CORFO, Chile, 1994.

g En esta clasificación se consideran microempresas, las que declaran un volumen de ventas inferior a 60000 dólares; pequeñas empresas entre 60 mil y 625 mil dólares; medianas entre 625 mil y 1250000 dólares, y grandes, más de 1250000 dólares.

h Corresponde a la participación en el empleo de los establecimientos entre 10 y 200 empleados.

i I. Aguilar, Revista Comercio Exterior, México, junio de 1995. 


\begin{tabular}{|c|c|c|c|c|c|}
\hline País & $\begin{array}{l}\text { Tamaño de las PYME } \\
\text { (según el número } \\
\text { de empleados) }\end{array}$ & $\begin{array}{c}\text { Número de estable- } \\
\text { cimientos } \\
(\% \text { del total })\end{array}$ & $\begin{array}{l}\text { Ventas } / \mathrm{pm} \\
(\% \text { del total })\end{array}$ & $\begin{array}{c}\text { Empleo } \\
\left({ }_{\text {Se del total })}\right.\end{array}$ & $\begin{array}{l}\text { Exportaciones } \\
(\% \text { del total })\end{array}$ \\
\hline \multirow{3}{*}{$\begin{array}{l}\text { Canadá } \\
(1990)\end{array}$} & $\begin{array}{c}\text { Manufactura } \\
(\leq 100 \text { empleados })\end{array}$ & & & $\begin{array}{l}52.3 \\
\leq 100 \text { empleados }\end{array}$ & \multirow{3}{*}{9.3} \\
\hline & & 99 & $\begin{array}{c}40 \% \\
\text { del PIB }\end{array}$ & - & \\
\hline & $\begin{array}{c}\text { Servicios } \\
(\leq 50 \text { empleados })\end{array}$ & & & $\begin{array}{c}43 \\
\leq 50 \text { empleados }\end{array}$ & \\
\hline $\begin{array}{l}\text { España } \\
(1989)\end{array}$ & $\leq 250$ empleados & 99.8 & $\begin{array}{c}64.25 \% \\
\text { de las ventas }\end{array}$ & 63.72 & 41.06 \\
\hline \multirow[t]{3}{*}{$\begin{array}{l}\text { Italia } \\
(1991)\end{array}$} & $\leq 200$ empleados & 97.6 & $\begin{array}{l}31.5 \% \text { del PIB } \\
(\$ 100 \text { empl.) }\end{array}$ & 54.7 & 22.6 \\
\hline & $\begin{array}{c}\text { Manufactura: } \\
(\leq 300 \text { empleados })\end{array}$ & & $\begin{array}{c}\text { De las ventas: } \\
\text { Empresas } \\
\text { manufactureras } \\
51.7\end{array}$ & \multirow{3}{*}{79.2} & \\
\hline & $\begin{array}{l}\text { Comercio mayorista: } \\
(\leq 100 \text { empleados })\end{array}$ & 99.1 & $\begin{array}{c}\text { Comercio mayorista: } \\
62.1\end{array}$ & & \\
\hline $\begin{array}{l}\text { Japón } \\
\text { (1991) }\end{array}$ & $\begin{array}{c}\text { Comercio minorista } \\
\text { y servicios: } \\
(\leq 50 \text { empleados })\end{array}$ & & $\begin{array}{c}\text { Comercio minorista: } \\
78\end{array}$ & & \\
\hline
\end{tabular}

Fuente: Domínguez (1996), quien cita como fuentes originarias las siguientes: Japan Small Business Corporation, 1995; Tacis Project, 1995; Canada House of Commons, 1994; Lorenzo y Calvo, 1994.

conjunto de microempresas y pequeñas empresas constituye, por abrumadora diferencia, la mayor parte del total de empresas existentes, y emplea un porcentaje muy alto de la mano de obra ocupada.

Esta situación es bastante similar en los países desarrollados, donde por razones obvias los criterios de clasificación de empresas según su tamaño consideran empresas con mayor número de empleados o superiores volúmenes de venta. Las PYME en Canadá, España, Italia y Japón (Domínguez, 1996) tienen una destacada participación en el número total de firmas del país respectivo, así como en el total de las ventas, el empleo y las exportaciones (cuadro 6).

Según datos de la Unión Europea (1994), en 1993 existían en ese espacio comunitario 17 millones de PYME, que suponían 67 millones de puestos de trabajo, de los cuales cerca de 30 millones correspondían a empresas con menos de 10 empleados.

En opinión de Bianchi (1996), las PYME desempeñan pues un papel crucial no sólo para promover el empleo, sino para garantizar el dinamismo de los mercados y el éxito de los acuerdos regionales de comercio y reforzar la estabilidad social de los países. En efecto, una estrategia orientada a estimular la "especialización y complementariedad" de la PYME en los acuerdos y en las aglomeraciones territoriales, resulta decisiva.

Como recuerda Bianchi (1996, p. 4), una rica y heterogénea literatura especializada muestra que el éxito de las pequeñas empresas en Europa se basa en aglomeraciones de firmas con diversas especialidades que trabajan en forma complementaria, de modo que el grupo es el sujeto colectivo que protagoniza la pugna competitiva.

En definitiva, en mercados abiertos las pequeñas empresas pueden ser competitivas: i) si avanzan en su especialización, es decir, si concentran el conocimiento productivo (tanto tecnológico como comercial u organizacional) en un rango específico de problemas, logrando ventajas de costos y liderazgo innovativo; ii) si operan al mismo tiempo en un contexto de cooperación, esto es, aceptan incrementar el costo vinculado a la especialización porque están seguras de que en la aglomeración territorial de empresas había alguna con una especialización complementaria, y iii) si las externalidades positivas de todo esto ayudan a cohesionar la aglomeración de empresas, evitando que ellas actúen a espaldas del grupo y permitiendo la entrada de nuevas iniciativas y empresas eficientes e innovadoras (Bianchi, 1996, p. 5). 
Dada la importancia y la mayor fragilidad del conjunto de empresas de pequeña dimensión en los diferentes sistemas productivos locales, se hace necesario asegurar la introducción de innovaciones tecnológicas y organizativas en los diferentes territorios. La elaboración de políticas de innovación tecnológica debe ser no sólo sectorial y centralizada, sino descentralizada o territorializada, a fin de recoger las condiciones específicas, los problemas y las potencialidades de cada uno de esos territorios, para facilitar la concertación estratégica de los actores sociales locales y alentar la construcción de la institucionalidad apropiada para la promoción económica y el fomento empresarial locales.

Para ello, la descentralización del Estado debe incluir contenidos sustantivos en términos de desarrollo económico, y dotar a las políticas de horizontalidad, selectividad, territorialidad y capacidad de promover la concertación estratégica entre los actores sociales (recuadro 1).
El diseño horizontal de las políticas, contrapuesto al vertical y centralista, apunta a crear oportunidades y un entorno propicio para emprendimientos innovadores. La selectividad de las políticas hace alusión a la necesidad de adaptarlas a los diferentes perfiles productivos y recursos potenciales del territorio, en contraposición al diseño generalista tradicional, que olvida el territorio y considera un espacio homogéneo y abstracto. Finalmente, la visión territorial concibe la economía nacional como un conjunto de economías locales y no solamente como un conjunto de sectores en un espacio abstracto.

En todo caso, la necesidad de considerar esta dimensión territorializada de la economía no excluye la de prestar continuada atención a las políticas de corte sectorial en aquellos segmentos que pueden mantener su dinamismo en los segmentos internacionales correspondientes. No hay antagonismo, sino falta de complementariedad en las políticas que se señalan, lo que debe superarse para alcanzar niveles de crecimiento económico y transformación productiva más compatibles con los avances deseados en materia de equidad.

Recuadro 1

COMPARACIONES ENTRE LAS POLÍTICAS DESCENTRALIZADAS Y LAS CENTRALIZADAS

Diseño descentralizado de políticas

Horizontalidad

Hay políticas de apoyo indirectas, orientadas de forma integral a crear oportunidades para emprendimientos innovadores

\section{Selectividad}

Las políticas se definen según los diferentes perfiles productivos de cada territorio

\section{Territorialidad}

La economía nacional se concibe como un conjunto de economías territoriales, y no sólo como un conjunto de sectores económicos

\section{Concertación}

Las políticas se elaboran conjuntamente con los diferentes actores sociales

\section{Diseño centralista de políticas}

\section{Verticalidad}

Las políticas se dictan desde el nivel central del Estado, normalmente bajo una lógica sectorial, y no suelen ser fruto de la concertación de los actores.

\section{Generalidad}

Las políticas se suponen válidas para cualquier espacio geográfico

\section{Carácter funcional/sectorial}

Se piensa en una economía nacional compuesta de sectores 


\section{Conclusiones: un planteamiento más completo para el desarrollo territorial}

Si el desarrollo económico es resultado del esfuerzo organizado de toda la sociedad y no puede seguir considerándose tan sólo como un ejercicio de planificación desde el Estado central, ni tampoco fruto de la actuación individual de las empresas, parece clara la necesidad de nuevos planteamientos más pragmáticos y menos ideologizados sobre el tema, en los cuales el territorio y el desarrollo local tengan un papel fundamental junto a las políticas macroeconómicas y sectoriales.

Crucial es también reinventar la gestión pública, a fin de incorporar una concepción integral de la innovación tecnológica como un proceso de cambio social, institucional y cultural, en el cual la concertación entre los diferentes actores sociales del territorio sustituya a los diseños fragmentarios y parciales de la anterior práctica planificadora centralista, y llevar a cabo una acción selectiva que identifique las correspondientes aglomeraciones o sistemas locales de empresas e incluya las políticas de desarrollo económico territorial como parte fundamental de la estrategia nacional de desarrollo.

En este sentido, la visión de largo plazo y la consideración de los diferentes niveles (micro, meso, meta y macro) de las políticas de desarrollo deben ser incorporadas en la gestión pública, que no es competencia sólo del Estado central, sino también de las administraciones públicas territoriales y del conjunto de actores sociales locales.

El abandono de las lógicas de la pasividad y del subsidio, sustituyéndolas por la incorporación de una cultura local innovativa, son componentes de este nuevo enfoque, al igual que un diseño institucional no burocrático dotado de agilidad y eficiencia operativa.

En conclusión, el nuevo planteamiento del desarrollo económico territorial destaca no solamente el interés por las grandes empresas y la inserción en las actividades dinámicas del núcleo globalizado de la economía mundial, que puede tener efectos importantes en determinadas regiones, sino también el de garantizar la expansión de las innovaciones tecnológicas y organizativas en el conjunto de sistemas productivos territoriales, a fin de potenciar su desarrollo endógeno. Para avanzar en ese sentido habrá que: i) orientar las actividades hacia la promoción del potencial de desarrollo endógeno y no sólo a la captación de inversiones foráneas;

ii) dar importancia a la dimensión territorial de la política tecnológica, para facilitar el fomento de las potencialidades endógenas de cada zona;

iii) prestar atención prioritaria a las pequeñas y medianas empresas y a las microempresas, introduciendo criterios de rentabilidad social y de generación de empleo e ingreso para la mayoría de la población, y no guiarse sólo por los estrechos criterios de la rentabilidad financiera inmediata;

iv) asegurar el acceso a los servicios avanzados a la producción en el entorno territorial;

v) afianzar las redes institucionales y acuerdos de cooperación y complementariedad territoriales en la construcción del entorno innovador apropiado, y

vi) en todo ello, tener en cuenta la sustentabilidad ambiental al considerar las diferentes opciones en materia de políticas y proyectos de desarrollo.

Este enfoque exhibe, pues, diferencias sustantivas con el planteamiento tradicional de las políticas de desarrollo territorial, tanto en lo relativo al diseño de la estrategia como a la determinación de los objetivos y mecanismos de acción, los tipos de gestión y los agentes participantes en ella (recuadro 2).

Así, mientras en el planteamiento tradicional predominan la visión funcional o sectorial y el interés por el desarrollo polarizado, el nuevo planteamiento hace hincapié en la importancia de la difusión del crecimiento económico y el empleo, con una visión territorial del proceso de desarrollo, y en la innovación, la calidad y la flexibilidad como criterios de actuación organizacional y productiva. A diferencia del planteamiento tradicional, el nuevo enfoque resalta más la calidad que el mero crecimiento cuantitativo y la concentración en grandes proyectos.

Asimismo, en el nuevo planteamiento la movilización del potencial endógeno y la utilización de recursos locales y externos reemplazan a las preocupaciones tradicionales por atraer inversiones foráneas y la suposición de movilidad de la fuerza de trabajo (Vázquez Barquero, 1993). 
Recuadro 2

POLÍTICAS DE DESARROLLO TERRITORIAL PREDOMINANTES

Planteamiento tradicional

Estrategia

dominante

Objetivos

Mecanismos

Organización

Agentes

Estado central

Grandes empresas
Nuevos planteamientos

Desarrollo difuso

(visión territorial)

Innovación, calidad y flexibilidad

Numerosos proyectos

Movilización del potencial endógeno

Utilización de los recursos locales y externos

Gestión local del desarrollo

Creación concertada de organizaciones

intermedias

Administraciones públicas territoriales

Estado central

PYME y microempresas

Actores sociales locales

Organismos intermedios

Entes supranacionales de integración económica
Por último, en cuanto al tipo de organización y los agentes principales, el nuevo planteamiento destaca la gestión local del desarrollo y la creación concertada de organizaciones y una institucionalidad de carácter intermedio o mesoeconómico, en lugar de la gestión y administración centralistas de los recursos, y subraya la importancia de las administraciones públicas terri- toriales, las PYME y las microempresas y el resto de la sociedad civil local, y no solamente del Estado central y las grandes empresas.

Desde esta perspectiva, lo pequeño no sólo es importante, sino que debe ser objeto primordial de atención como factor de desarrollo económico, social y territorial en América Latina y el Caribe.

\section{Bibliografía}

Alburquerque, F. (1996a): Desarrollo económico local y difusión del progreso técnico, Santiago de Chile, Instituto Latinoamericano y del Caribe de Planificación Económica y Social (ILPES). (1996b): Globalización, competitividad y desarrollo económico local, Santiago de Chile, ILPES.

Banco Mundial (1996): The World Bank Atlas, Washington, D.C. Becattini, G. y E. Rullani (1996): Sistemas productivos locales y mercado global, Información comercial española, $\mathrm{N}^{\circ} 754$, Madrid, Ministerio de Economía y Hacienda, junio.

Bianchi, P. (1996): Nuevo enfoque en el diseño de políticas para las PYME'S: aprendiendo de la experiencia europea, Documento de trabajo $\mathrm{N}^{\circ} 72$, Buenos Aires, Oficina de la CEPAL en Buenos Aires.

CEPAL (Comisión Económica para América Latina y el Caribe) (1996): Balance preliminar de la economía de América Lati- na y el Caribe, 1996, LC/G.1947-P, Santiago de Chile. Publicación de las Naciones Unidas, $\mathrm{N}^{\circ}$ de venta S.96.II.G.13.

Domínguez, R. (1996): Promoción y reestructuración de pequeñas y medianas empresas en Canadá, España, Italia y Japón. Temas para el debate en América Latina, Washington, D.C, Banco Interamericano de Desarrollo (BID), División de Infraestructura y Mercados Financieros.

Esser, K., W. Hillebrand, D. Messner y J. Meyer-Stamer (1996): Competitividad sistémica: nuevos desafíos para las empresas y la política, Revista de la CEPAL, $\mathrm{N}^{\circ}$ 59, LC/G.1931-P, Santiago de Chile, CEPAL

Ffrench-Davis, R. (1996a): Políticas públicas y globalización económica, Santiago de Chile, CEPAL.

(1996b): Efectos económicos de la globalización. Una visión latinoamericana, La Época, Santiago de Chile, 29 de septiembre . 
Messner, D. (1996): Dimensiones espaciales de la competitividad internacional, Revista latinoamericana de estudios del trabajo, Santiago de Chile, Facultad Latinoamericana de Ciencias Sociales (FLACSO)
Unión Europea (1994): The European Observatoiy for SMEs, Second Annual Repon, Bruselas.

Vázquez Barquero, A. (1993): Política económica local, Madrid, Ed. Pirámide. 